\title{
El movimiento de Mayo del 68 y las mujeres
}

\section{The May 68 movement and the women}

\author{
Denesy Palacios-Jiménez ${ }^{1^{*}}$ \\ ${ }^{1}$ Universidad Nacional Hermilio Valdizán de Huánuco \\ *Correo para correspondencia: denesypalacios@gmail.com
}

\section{RESUMEN}

El artículo destaca el significado y el espíritu del movimiento estudiantil de Mayo del 68 y su aporte hacia los derechos y el liderazgo de las mujeres, así como su relación con el movimiento feminista. Explica, primero, el inicio y auge de la rebelión estudiantil; segundo, los diversos componentes que influyen; tercero, el significado, la trascendencia, el espíritu de lucha, el liderazgo, el impacto en la población y en la clase política, y la repercusión internacional; y cuarto, el aporte o impacto en los derechos, en la participación, protagonismo y liderazgo de las mujeres, así como en su relación con el origen y evolución del movimiento feminista en el mundo.

Palabras clave: mayo del 68, rebelión estudiantil, Universidad de Nanterre, Universidad la Sorbona, mujeres, movimiento feminista.

\section{ABSTRACT}

The article highlights the meaning and spirit of the May 68 student movement and its contribution to women's rights and leadership, as well as its relationship with the feminist movement. It explains, first, the beginning and height of the student rebellion; second, the various influencing components; third, the meaning, the significance, the fighting spirit, the leadership, the impact on the population and the political class, and the international repercussion; and fourth, the contribution or impact on the rights, on the participation, protagonism and leadership of women, as well as on their relationship with the origin and evolution of the feminist movement in the world.

Keywords: may 68, student rebellion, University of Nanterre, Sorbonne University, women, feminist movement. 


\section{INTRODUCCIÓN}

El movimiento de Mayo del 68 es el referente mundial más notorio e impactante de la rebelión estudiantil contra una sociedad autoritaria, limitante de derechos fundamentales, de relaciones de dominio hacia la mujer, y que entre mayo y junio de 1968 se manifiesta en una masiva ola protestas y movilizaciones, desatadas por los estudiantes de las universidades de Nanterre y la Sorbona con el apoyo de los obreros y todos los ciudadanos, que paraliza Francia, genera una grave política que lleva al cierre de la Asamblea Nacional, a la consecuente convocatoria de elecciones y después a un referéndum que termina con la renuncia y la carrera política del presidente Charles de Gaulle.

La acción nace en una periférica universidad ubicada en un barrio obrero, Nanterre, próximo a París, luego se expande a la Universidad la Sorbona y después a toda Francia y al mundo, y genera una escalada de multitudinarias revueltas internacionales que dan origen a los otros Mayos del 68. Su onda expansiva y su influencia han sido impredecibles, tanto que hasta hoy su espíritu de lucha está presente en las protestas de los jóvenes y su impacto se ha convertido en una herencia favorable para la población francesa y en una amenaza permanente para su clase política y, por supuesto, de todos los países. La histórica Primavera de Praga (que provocó la invasión rusa en agosto de 1968) y la más reciente Primavera Árabe (2010-2012), son solo dos ejemplos del impacto mundial del espíritu de rebeldía y de la huella de Mayo del 68.

El Mayo francés, desde sus antecedentes, causas, móviles, contextos, protagonistas, hasta sus impresionantes efectos, está lleno de enfoques múltiples, de diversas miradas, de complejidades, de contrastes, de contradicciones, de concepciones teóricas, de expresiones culturales y contraculturales, de nuevas manifestaciones teóricas, culturales, artísticas, de enigmas, en fin, que los autores coinciden que se trata de una historia difícil de contar. Solo al culminar 1968 se habían publicado más de cincuenta libros sobre el movimiento juvenil, como recuerda Sánchez-Prieto (2001, p. 109). Hoy han pasado cincuenta años y se sigue publicando sobre el acontecimiento. Una rebeldía estudiantil que exigía una sociedad libre y justa a través de un reclamo reivindicativo y un discurso inspirado en frases creativas, provocadoras y desafiantes, y que pese a todo el esfuerzo de lucha, fue neutralizado y controlado por el poder del gobierno. Su lucha fue aplacada, pero no su espíritu de rebeldía, su estela de indignación y de impotencia. Estas huellas trascendieron fronteras y han quedado impregnadas en el mundo. Es la viva herencia de Mayo del 68.

El movimiento en su desarrollo transcurre tres fases: la fase estudiantil, la fase social (que se da con la movilización obrera propiciada por la protesta estudiantil) y la fase política (con la intervención del gobierno y la disolución de la Asamblea Nacional). El tema a desarrollar se centra en la fase estudiantil. Destaca, en primer lugar, la esencia y espíritu de rebeldía del movimiento estudiantil, su influencia y repercusión internacional, y su liderazgo; y en segundo lugar, el impacto de este movimiento en los derechos, en la participación, protagonismo y liderazgo de las mujeres, así como en su relación con el movimiento feminista. El propósito es explicar la contribución del movimiento estudiantil de Mayo del 68 hacia las mujeres, uno de los temas aún más polémicos en el debate del legado histórico de esta rebelión.

\section{Mayo francés}

Los estudiantes franceses de la Universidad de Nanterre habían emprendido durante 1967 una serie de protestas para exigir mayores libertades y dejar sin efecto la cuestionada reforma de la educación superior impulsada por el gobierno. Un año después, el 22 de marzo de 1968, en protesta por la detención de sus compañeros durante la manifestación 
contra de la guerra de Vietnam, 142 estudiantes, entre quienes estuvo uno de los principales líderes del Mayo francés, Daniel Cohn-Bendit, Dani el Rojo, ocupan toda la noche el edificio administrativo de dicha universidad.

El hecho lleva a la formación del emblemático Movimiento 22 de Marzo, conformado por grupos llamados "indignados", por anarquistas, libertarios y diversos militantes de izquierda, que desata constantes acciones de protestas y enfrentamientos en la casa de estudios. Ellos, en su manifiesto, se propusieron ir "de la crítica de la universidad a la universidad crítica".

Las autoridades al perder el control de estas acciones, cierran a pocas semanas, el 2 de mayo, la Universidad de Nanterre. Al día siguiente, los manifestantes reciben el pleno respaldo de los estudiantes de la Universidad la Sorbona, quienes protestan masivamente y toman las calles de París. En respuesta, la policía invade el claustro universitario y así provoca una ola de protestas y barricadas estudiantiles, tanto en París como en el Barrio Latino, zona cercana a la capital francesa y de mayoría obrera e inmigrante, escenario de la Universidad de Nanterre y bastión de los estudiantes.

A los reclamos de los universitarios se suman de inmediato los alumnos de secundaria, los obreros industriales, los controladores aéreos, los trabajadores del carbón, del transporte, de la industria automotriz, del gas y la electricidad, los agricultores, los sindicatos, el Partido Comunista Francés y los demás partidos tradicionales de izquierda, los periodistas de radio y televisión (afectados por la censura del gobierno), los intelectuales de izquierda, los artistas, cineastas y escritores contraculturales. Aun el Festival de Cannes fue suspendido.

La revuelta estudiantil, con noches de barricadas como las ocurridas el 10 y 11 de mayo, estremeció al gobierno y a todos los franceses. El 13 de mayo los sindicatos salen en apoyo a los estudiantes y convocan a multitudinarias movilizaciones, en tanto que al día siguiente los obreros inician una ola de huelgas hasta paralizar al país. El 22 de mayo Francia queda paralizada con más de 9 millones de trabajadores en huelga. Las fábricas, los servicios de transportes, los trenes, los aeropuertos, los centros de abastos dejaron de funcionar. La huelga general se apodera de Francia. Los estudiantes, seguidos por los sindicatos y los obreros habían hecho de las calles su poder. Habían puesto al país en la anarquía y el desgobierno, y desafiado al líder de la Quinta República, el presidente Charles de Gaulle.

El gobierno pese a los Acuerdos de Grenelle, mediante cuyos compromisos impulsa amplios beneficios para los trabajadores, como el aumento del salario mínimo (en un $35 \%$ ) y de los días a vacaciones; no pudo sobreponerse a la crisis política. Cae el gabinete del primer ministro Georges Pompidou. El 30 de mayo el presidente De Gaulle disuelve la Asamblea Nacional y convoca a elecciones legislativas anticipadas. Su agrupación política gana los comicios. En 1969, realiza el referéndum para las reformas de regionalización y del Senado, que el mismo plantea como un plebiscito sobre su gestión al anunciar el retiro de la presidencia en caso de perder. El pueblo, aún impactado por la crisis, esta vez le da un rotundo rechazo. Tras la derrota, De Gaulle renuncia al cargo y se retira de la política.

\section{Rebeldía estudiantil inspirada}

Es lo que fue Mayo del 68. El movimiento de protesta estudiantil forjado en este histórico momento de lucha, sin embargo, no fue exclusivo de los franceses, este emerge por el impacto de otros movimientos internacionales. Contribuyen al levantamiento francés que estalla en mayo y junio de 1968, el Movimiento por la Libertad de Expresión (Free Speech Movement) en Berkeley, Estados Unidos, entre 1961 y 1964, y todos los movimientos que desde 1961 en dicho país impulsan las cadenas de protestas globales contra la guerra de 
Vietnam. También repercuten los movimientos estadounidenses de los sesenta contra el racismo hacia la población negra. El asesinato de Martin Luther King el 4 de abril de1968 en pleno auge de la lucha por los derechos civiles, fue uno de los principales detonantes internacionales.

En Ámsterdam, Holanda, influye el movimiento provo, fenómeno anarquista, contracultural, libertario, antimonárquico y detractor del consumismo de la bonanza de la posguerra, con sus protestas que empiezan en1960 y que remecen en Europa en 1966.

En Alemania, Fráncfort, proyectan la rebeldía los estudiantes de la denominada generación del 68 que a través de sus protestas de 1968 se enfrentan al gobierno en rechazo a la sociedad conservadora, tradicional, de normas rígidas, así como al autoritarismo político alentado por exfuncionarios nazis y a toda forma de autoridad. La rebelión estudiantil, que generó cambios políticos y sociales en Alemania, se gesta con el asesinato del estudiante Benno Ohnesorg, el 2 de junio de 1967, y alcanza su mayor acción el 11 de abril de 1968 con el intento de asesinato de Rudi Dutschke, el más importante y mediático líder, gran orador y carismático quien expulsado de su país por el gobierno, fallece en 1979 en Dinamarca por la secuela del atentado.

Influyentes protestas se presentan asimismo en Italia (Milán), y entre otras, en Checoslovaquia con la emblemática Primavera de Praga, que se inicia el 5 de enero de 1968 con la elección del reformista Alexander Dubcek como primer secretario del Partido Comunista de Checoslovaquia, y continúa hasta el 21 de agosto, cuando la Unión Soviética y demás miembros de Pacto de Varsovia invaden el país con sus miles de tanques y soldados para reprimir las reformas de intento de democratización emprendidas y que amenazaban la expansión del comunismo en el mundo. Ya en abril, como destaca Otero (2008), se eliminaba la censura de prensa y radio, se reconocía el derecho de huelga, la libertad de movimiento de las personas, el pluralismo político y se ponían en marcha toda una serie de medidas descentralizadoras de la economía y la administración.

En la propia Francia hubo dos anteriores rebeliones estudiantiles y civiles decisivos, lo ocurrido en Estrasburgo en 1966 y lo sucedido en enero de 1968, cuando el gremio del cine, estudiantes, intelectuales y ciudadanos se apoderan de las calles para protestar contra la destitución del director de la Cinemateca Francesa, Henri Langlois. Asimismo, hay que destacar las violentas huelgas de jóvenes ocurridas en 1967 en Caen, Le Mans y otras ciudades francesas, acciones que para algunos fue el detonante principal de Mayo del 68.

Los estudiantes de Mayo francés se ven influidos además por los movimientos revolucionarios y de liberación de los países tercermundistas, como las acciones de lucha lideradas por el Frente de Liberación Nacional de Argelia contra la colonización francesa, el movimiento de la Revolución cubana, el Movimiento de Liberación de Palestina (Al-Fatah) y la guerra de Vietnam, conflicto que entre 1965 y 1969 desata las más fervientes protestas universitarias en Estados Unidos y Europa.

Diversos autores destacan la guerra de Vietnam como detonante del móvil directo de las protestas de Mayo del 68. Sánchez-Prieto (2001) coincide con Albiac cuando sostiene que este movimiento estudiantil empezó en cierta forma no en Nanterre, sino en Saijón. Albiac (1993) considera que sin la ofensiva del Tet y la imagen de los campesinos vietnamitas enfrentándose a la más prodigiosa máquina técnológicomilitar del siglo, el sueño de mayo tal vez no hubiera sido posible.

Es que la operación militar comunista norvietnamita perpetrada en enero de 1968 contra el ejército de Vietnam del Sur, que provoca el sobredimensionado contrataque de las fuerzas 
estadounidenses, termina victimizando a los atacantes. Si bien la ofensiva no llega a prosperar, debilita a las fuerzas americanas y al gobierno, porque pierden el apoyo público de los ciudadanos del mundo que respaldaban la reacción anticomunista. Fue una derrota moral para los Estados Unidos.

Rieznik, Rabey, Poy, Duarte y Bruno (2010) relatan que la masacre ocurrida en abril de 1968 contra mujeres y niños en la aldea de My Lai provoca una conmoción planetaria, y que aquella famosa foto de niños desesperados corriendo desnudos con el telón de fondo de una ruta bombardeada se transforma en símbolo de la brutalidad imperialista.

Los universitarios franceses en medio de este ambiente gestan diversas acciones de protestas en favor de la paz al ritmo de las luchas por sus propias reivindicaciones.

El espíritu de rebeldía de los jóvenes a la vez se nutre de los movimientos contestatarios, transgresores, contraculturales de la época, como los beatniks (término acuñado desde 1964 para parodiar y referirse de manera despectiva a los beat), la generación beat (grupo de escritores estadounidenses que surge a mediados de la década de los cuarenta), los hippies, los happening, los underground. También se ve influido por el movimiento artísticointelectual de la Internacional Situacionista, la corriente de la antipsiquiatría, el avance de la escuela de Fráncfort, la que cuestiona el consumismo, la cultura de masas, a través de intelectuales como Theodoro Adorno y, entre otros, Herbert Marcuse, autor del influyente ensayo El hombre unidimensional, publicado en 1964.

El término antipsiquiatría es usado por primera vez en 1967 por David Cooper. Se trata de un movimiento influenciado por el marxismo que rechaza la psiquiatría convencional, porque de acuerdo con la concepción de Cooper, es un instrumento del capitalismo y que tiene por objeto reprimir a los rebeldes, a los que se resisten al conformismo burgués.

Influyeron además en ellos las ideas de izquierda heterodoxas que estaban en apogeo en el momento, como el anarquismo, el trotskismo, el maoísmo, el castrismo. Estas se mostraban como alternativa frente al Partido Comunista tradicional y a los sindicatos que tal partido controlaba.

\section{El espíritu del movimiento}

Mayo del 68 es la gesta de protestas estudiantiles que estalla en Nanterre y París, y que de inmediato su onda de indignación se expande por toda Francia, Europa y todo el mundo. Su impacto global fue tanto que hasta hoy, a más de 50 años, sigue siendo el referente de las protestas estudiantiles, de la rebeldía juvenil, del poder de las calles, de la acción libertaria, de las luchas por el cambio de la vida social.

Sánchez-Prieto (2018), siguiendo a Pierre Norra quien destaca que el 68 es una historia imposible de contar, sostiene que el Mayo francés "se presenta desde el primer instante como historia de difícil explicación: supuso el regreso del acontecimiento y fue un acontecimiento imprevisible" (p. 109).

Al evocar el medio siglo del acontecimiento, Dusster (2018) define a Mayo del 68 como la "revolución que no prosperó pero que fue la protesta más influyente en las décadas posteriores".

Resalta que fue una revuelta que no perseguía llegar al poder sino cambiar la sociedad, que su espíritu era luchar contra todas las discriminaciones, que se trató de un movimiento para reivindicar más libertades en la esfera privada que cuestionó la esfera pública. No cambió el 
poder ni el sistema, prosigue, pero "transformó ideas y valores morales". Además, "nadie lo intuyo, nadie pudo detenerlo", reflexiona.

Rieznik et al. (2010) consideran que Mayo del 68 fue el segundo estallido revolucionario francés del siglo XX, después de las protestas de 1936, donde el proletariado también había paralizado toda Francia con una formidable huelga general, que fue desactivada entonces a partir de importantes concesiones - vacaciones, semana de trabajo de cuarenta horas, reconocimiento de la organización sindical en las fábricas - pero, sobre todo, debido a la colaboración contrarrevolucionaria del estalinismo para sostener a un gobierno "socialista", dirigido por León Blum, que asumió la tarea, no de desmantelar al Estado capitalista, sino de sostenerlo.

Afirman que estos "socialistas" apoyaron después la emergencia de un gobierno de "salvación nacional" de colaboración con el nazismo. Luego de tanto empeño contrarrevolucionario, manifiestan que el socialismo francés queda prácticamente disuelto, pero no el proletariado, que revive su gesta "por la mediación de una joven generación obrera y con la novedad de un movimiento estudiantil de masas, como no había existido hasta entonces" (p. 12).

El filósofo Francisco Fernández Buey (2008), el más destacado dirigente del movimiento estudiantil de la resistencia antifranquista, define que este movimiento que empieza como un memorial de quejas fue un ensayo general revolucionario que asustó a la mayoría de la sociedad francesa del momento.

Sostiene que fue un susto y no una gran fiesta lúdica como han tratado de banalizar y descalificar los detractores. Explica que se asustaron los burgueses que vieron peligrar sus propiedades; los pequeños burgueses que vieron peligrar sus privilegios y los de sus hijos; se asustó De Gaulle que tuvo que echar mano del ejército; el Partido Socialista que creía pasada la época de las revoluciones; el Partido Comunista, que aún hablaba de revolución en general pero no de esa; se asustaron los sindicatos que se vieron rebasados por la espontaneidad de los consejistas en las ocupaciones de fábricas y criticados por los estudiantes por su inconsecuencia; y se asustó una parte de los intelectuales y profesionales que vieron con buenos ojos el arranque de los acontecimientos y todavía se solidarizaron con el movimiento en el momento de la represión, pero que, según el autor, no pudieron aguantar la acusación de ser unos mandarines al servicio del sistema, una acusación cada vez más repetida por los comités de obreros y estudiantes.

Para Fernández Buey (2008), Mayo del 68 representó el momento culminante de uno de los movimientos sociales más activos e interesantes de la segunda mitad del siglo XX.

Lamenta, sin embargo, la manipulación mediática para desnaturalizar y trivializar el movimiento. Cuestiona que de la gran depresión producida por la derrota del 68, y no de las ideas que se expresaron en la protesta, haya salido el llamado individualismo contemporáneo. Rechaza que se trate de convencer que el individualismo contemporáneo es hijo de Mayo del 68. "Nada más lejos de la verdad", dice, porque el individualismo contemporáneo "es hijo de los que vencieron a los estudiantes y obreros rebeldes del 68"; o tal vez "el hijo pródigo del matrimonio de estos con quienes, habiendo perdido, se resignaron para acomodarse a la derrota".

También cuestiona que se haya trivializado el eslogan más célebre del Mayo francés, "La imaginación al poder", para estigmatizarlo como una simple protesta lúdica. Precisa que la frase era una contundente declaración de principios en la entrada principal de la Sorbona de París y que decía: "Queremos que la revolución que comienza liquide no solo la sociedad 
capitalista sino también la sociedad industrial. La sociedad de consumo morirá de muerte violenta. La sociedad de la alienación desaparecerá de la historia. Estamos inventando un mundo nuevo original. La imaginación al poder".

Era el sentir de cambio genuino de los jóvenes que desde una posición radical e independiente del Partido Comunista, de la central sindical comunista y de toda resistencia, pretendía el cambio del statu quo de la sociedad.

Este sentimiento de cambio, de rebeldía frente a toda forma de autoritarismo, más allá de su posición radical, les llevó a los jóvenes a emerger como actor social y político, a convertirse en líderes de cambio y a desplazar de tal liderazgo a los obreros -actores principales en la época y sujetos revolucionarios del comunismo-, quienes se sumaron a la protesta aun a pesar de la resistencia inicial de los líderes sindicales y del Partido Comunista.

Los jóvenes en la época padecían el malestar social derivado del proceso de modernización económica de los llamados treinta gloriosos años (1945 a 1977), de la prosperidad económica de la posguerra, del estado del bienestar, de la sociedad de consumo reforzada por los medios de comunicación, panorama que contrastó con las nuevas necesidades de la generación del baby boom, con el desempleo, la mayor preocupación por acceder a la educación universitaria, el progresivo ingreso de las mujeres de clases medias a la vida educativa y laboral.

Había, sin duda, crisis del sistema que atender, en especial en la educación universitaria. La misma Universidad de Nanterre era reflejo de ello, que de acuerdo con Crouzet (como se citó en Rieznik et al., 2010, p. 17), había sido fundada pocos años antes, en el Barrio Latino, en un "oscuro barrio" de la periferia parisina, "con el propósito de aliviar la sobrepoblación de la Sorbona, desbordada por el constante incremento de la población estudiantil".

Rieznik et al. (2010) explican que el campus de la Universidad de Nanterre "era una suerte de paraje desolado", por lo que el gobierno prohíbe en la Sorbona la inscripción de estudiantes de varios barrios de París, los más próximos a Nanterre, para obligar a una "inscripción forzada" en la nueva universidad, y para compensar esta especie de ultimátum tuvo que ofrecer instalaciones más amplias y una mejor relación entre el número de profesores y estudiantes (p. 17).

Pero manifiestan que la situación se deterioró rápidamente por el aumento de la matrícula estudiantil, que no cesaba de crecer: 2000 estudiantes en el año lectivo 1964-1965; 8000 en 1966-1967.

Expresan que Nanterre sufría el fenómeno más general de la "sobreproducción" universitaria, y que el mal llamado "boom económico de la posguerra" manifestaba sus límites en la imposibilidad de utilizar sus recursos más calificados (p. 17).

Crecía, según ellos, el número de jóvenes profesionales sin oportunidades de trabajo y se hacía sentir la asfixia de recursos económicos: "el mundo universitario se desenvolvía en una rutina burocrática y regimentadora contra la cual se evidenciaba una creciente inquietud estudiantil" (p. 17).

Relatan que el clima se tornó más caldeado sobre el final de 1967, cuando el gobierno anunció una reforma universitaria que incluía "diversas medidas limitacionistas y la creación de carreras cortas para evacuar las pobladas aulas de la enseñanza superior" (p. 18). Fue el denominado plan Fouchet, en alusión al entonces ministro de Educación Nacional promotor de la iniciativa, Christian Fouchet, acción considerada como uno de los principales 
detonantes de la revuelta estudiantil.

El malestar era preocupante, pero los jóvenes buscaban más el cambio de nueva convivencia de la sociedad. Sánchez-Prieto (2001) considera que la crisis respondía más a un patrón cultural en todos los países desarrollados: los valores tradicionales son rechazados; la autoridad familiar, profesoral o patronal es contestada; el prestigio de las ideas de izquierda heterodoxas alcanza todo su apogeo. La lucha contra el autoritarismo de todo tipo y el imperialismo fue la característica del Mayo francés y de los demás movimientos estudiantiles, según Fernández Buey (2008).

El reconocido periodista peruano César Hildebrandt (2008), en un artículo de homenaje a la generación del 68 por los 40 años, reivindica la esencia del espíritu estudiantil del movimiento de Mayo francés. Destaca que a los jóvenes de esta generación les disgustaba el mundo pero disfrutaban mucho de la gente y muchos de ellos "no sentían vergüenza amando como animales, gritando como descubridores, viviendo al filo de la navaja y contradiciéndose groseramente".

Resalta que los del 68 querían un mundo mejor "pero antes de quererlo, ellos mismos se hicieron mejores". Y se hicieron mejores, añade, con "el método más sencillo: sintiendo que la injusticia nos concierne y que el planeta es uno solo, lleno de prójimos y de esperanza".

Lamenta, sin embargo, que este espíritu haya ido perdiendo fuerza. Sostiene que la "alegría constructora" de Mayo del 68 fue languideciendo por tres factores: primero, por errores del comunismo que devino en "sucio estalinismo armado contra el pueblo"; segundo, por la degeneración de la socialdemocracia que terminó convirtiéndose en el poder "en una exquisita rama de la derecha"; y tercero, por la "colosal operación mundial" que la derecha financió para imponer su hegemonía global.

Hildebrandt (2008) confiesa que nunca terminará de agradecer a la casualidad de haber pertenecido a la generación del 68. Porque no había duda, reflexiona: "los del 68 estábamos vivos y odiábamos la indiferencia".

Pero el espíritu de lucha de los jóvenes del 68 también ha quedado marcado en la mayoría de los franceses. Un sondeo publicado tras los 40 años de Mayo 68 refleja que el $78 \%$ de la población ve positiva la herencia del movimiento (Struyf, 2008, p. 1).

Su impacto, además, aún está latente en los sectores ultraconservadores y en la clase política francesa, de ahí la amenaza en campaña presidencial en el 2007 de Nicolás Sarkozy de acabar con el espíritu de la rebeldía juvenil, con ese legado que él llama "la inmortal herencia a liquidar". Se trata de saber, dijo, "si la herencia de Mayo del 68 debe ser perpetuada o si debe ser liquidada de una vez por todas", y anunció: "Yo quiero pasar la página de Mayo del 68" (Rieznik et al., 2010, p. 5).

Y no es para menos la fuerza del impacto, porque la acción del movimiento juvenil no se limitó a Francia, se extendió a diversos países industrializados y a todo el mundo. Fernández Buey (2008) sintetiza que Mayo del 68 se extendió en los cuatro puntos cardinales: en Berkeley y en Milán, en México y en Barcelona y Madrid, en Berlín y en Tokio, en Londres y en Praga y en Varsovia.

Rieznik et al. (2010) destacan que Mayo francés es uno de los hitos que conmovieron al mundo en 1968, al igual que la guerra de Vietnam, la Primavera de Praga y las protestas y el consiguiente asesinato masivo de estudiantes el 2 de octubre en Tlatelolco (México). Pero también estallaron otros más, los Mayos se multiplicaron, según precisan, en Europa, con el 
"verano caliente", Italia, España, Inglaterra, Alemania, Polonia; en Asia, Japón, China alcanzaba el punto más alto de la Revolución Cultural.

Lo mismo ocurrió en América, como ellos refieren, en las fronteras argentinas el proletariado uruguayo se levantaba contra el gobierno creando una situación revolucionaria; en Bolivia, se desarrollaba la guerrilla de Inti Peredo contra la agónica dictadura del general Barrientos (Guido Peredo fue asesinado el 9 de septiembre de 1969 y participó de las acciones guerrilleras de Ernesto Che Guevara, ejecutado el 9 de octubre de1967); en Brasil, el estudiantado se levantaba contra su propia dictadura ocupando las calles de San Pablo; en Argentina, empezaban las huelgas que culminarían en el Cordobazo (29 y 30 de mayo de1969); en El Salvador una huelga general de maestros hacía temblar el país. Ello sin considerar lo que vino en la década posterior.

El impacto, no obstante, fue mayor y duradero por el cambio de sociedad que planteaba. Joaquín Estefanía (2018) afirma que Mayo del 68 acunó muchas causas diferentes como el ecologismo, la libertad sexual, la educación igualitaria o el feminismo y todas fueron impulsadas como nunca antes.

Dusster (2018) resalta que fue una eclosión de libertades y causas, y que los derechos civiles, el antinuclearismo, la revolución sexual, el antibelicismo tuvieron cobijo bajo un paraguas que reclamaba una nueva moral y una nueva sexualidad. Las perspectivas libertarias, precisa Dusster, se canalizaron posteriormente en el feminismo, la ecología, la lucha contra el racismo.

Prudhomme (2018) reencuentra el espíritu de Mayo del 68 aun en la solidaridad con los refugiados, por una "virulenta denuncia en las fronteras" expresada y por los eslóganes que además quedaron: "Pasamos de las fronteras" y "Todos somos judíos alemanes", por ejemplo.

\section{Las mujeres de Mayo del 68}

La lucha contra el autoritarismo docente, contra la represión hacia la convivencia social entre alumnos y alumnas en la Universidad de Nanterre, en particular, fueron las iniciales acciones de protestas internas que llevaron a los estudiantes de esta casa de estudios a la masificación del movimiento de Mayo del 68.

Francia, antes de este acontecimiento, era una sociedad autoritaria, represora, contra la mujer, contra los jóvenes. Las mujeres tenían que pedir permiso a sus esposos para poder trabajar; los jóvenes eran reprimidos por el Estado en sus libertades individuales; los alumnos no podían siquiera visitar a las alumnas en las residencias universitarias, tal como denunciaron los estudiantes de la Universidad de Nanterre entre sus primeros reclamos institucionales; los universitarios estudiaban en un ambiente donde los catedráticos, como recuerda Dusster (2018), eran inaccesibles, daban clases con togas y cuyas jerarquía y autoridad eran incuestionables; las relaciones y la moral estaban sometidas a reglas rígidas y puritanas, como manifiesta Philippe Leduc (Stryf, 2008, p.2), activo participante de la protesta. Una sociedad contra la que lucharon los jóvenes.

La destacada filósofa Florence Prudhomme (2018), también activa participante de Mayo del 68, en su testimonio en el coloquio conmemorativo "Sobre las huellas del Movimiento 22 de Marzo", organizado el 23 de marzo de 2018 en la Universidad de Nanterre por el referido movimiento; confiesa que antes del 68 , en el 64,65 , vivía el espíritu de rebeldía frente a la moral rígida y autoritaria de sus padres y que su conciencia política proviene de esa época en la que fue alejada por ellos al extranjero para refrenar y olvidar tanto sus primeros 
amores como sus deseos de niña, y dedicarse exclusivamente a los estudios. No obstante, en el 66, añade, vuelve a Francia y continúa sus estudios de Filosofía en Nanterre.

Relata que la sociedad era "encorsetada, sofocante, irrespirable, basada en estrictas relaciones de dominación" y que las relaciones de dominación fueron sacudidas en las universidades, en las fábricas, en los hospitales, pero lamentablemente "con excepción de las que regían las relaciones entre los hombres y las mujeres".

Manifiesta que las reivindicaciones de las mujeres a nivel social, económico y político no se tomaban en cuenta, menos las relacionadas con su cuerpo y su sexualidad; sin embargo, la vida sexual, según ella, estaba abiertamente a la orden del día, aunque también los abortos clandestinos. Antes de 1967, precisa, Francia registraba cada año más de 200000 abortos clandestinos.

Badenes (2018) afirma que el Partido Comunista Francés (PCF) y los principales sindicatos obreros defendían el carácter emancipador del trabajo femenino, pero se mostraban muy reacios a permitir la libertad de contracepción y el aborto, al menos su cúpula directiva. El control de la natalidad, según ella, era percibido por estos como "un dardo envenenado que lanzaba la burguesía capitalista para debilitar a la clase obrera" (56).

Lamenta que el impulso emprendido por El segundo sexo, el influyente ensayo escrito en 1949 por Simone de Beauvoir, haya sido "bloqueado durante décadas por esta visión rancia de la izquierda francesa, que veía el feminismo como una forma de desunión" (56).

Por ello, Prudhomme (2018) define que Mayo francés fue un movimiento insurreccional, una toma deslumbradora de libertad, que trastornó la vida de un número inmenso de personas.

Es indudable que la rebeldía juvenil de Mayo del 68 deja su mayor legado en el cambio de la sociedad en cuestión y en la reivindicación, en este caso, de los derechos de la mujer. La población francesa reconoce en el ya mencionado sondeo que entre los logros del acontecimiento está el reparto de tareas entre hombres y mujeres (80\%), la sexualidad (72 $\%$ y las relaciones padres-hijos (82 \%) (Struyf, 2008, p. 1).

Según Dusster (2018), si bien las mujeres no visibilizaron un liderazgo individual, su presencia en las calles y en las protestas sí se hizo notar. Adquirieron protagonismo político colectivo.

Fernández Buey (2008), en el mismo sentido, establece que hubo participación de las mujeres en Mayo del 68, pero considera "inexacto" que haya existido liderazgo femenino y que la rebelión estudiantil haya sido el origen directo del feminismo y de los demás movimientos sociales nuevos, críticos y alternativos.

Plantea que antiautoritarismo y antimperialismo son rasgos que aparecen reiteradamente y con mucha fuerza en Mayo francés y en todos los movimientos estudiantiles de entonces; y antiautoritarismo no solo en el sentido de la crítica de la autoridad de la familia, del Estado, de las iglesias y del mandarinato existente en la universidad, sino también como autonomía radical respecto de todos los partidos políticos del arco parlamentario; en tanto que antimperialismo entendido como oposición a los dos modelos socioeconómicos cristalizados durante la Guerra Fría.

En líneas generales considera que estos rasgos pasarían, ya en los setenta, a la crítica feminista del patriarcado, a la crítica ecologista de la sociedad industrial y productivista y a la crítica pacifista de la estrategia militar del terror. 
Aclara, sin embargo, que si por movimientos sociales nuevos entendemos lo que por entonces empezó a llamarse "nuevo feminismo", o ecologismo o pacifismo, Mayo del 68 tuvo muy poco que ver con ello. Para probarlo, dice, basta ver los documentos escritos y orales que han quedado de las asambleas de Nanterre y la Sorbona: "ahí hay muy poco feminismo, casi nada de ecologismo y, desde luego, nada de pacifismo".

Fernández Buey (2008) afirma que sintomáticamente no hay ni una sola mujer entre los líderes destacados del movimiento y las grabaciones que han quedado (cintas magnetofónicas y cinematográficas) muestran que a las mujeres apenas se las dejaba tomar la palabra en los comités. También precisa que es verdad que se citaba a Wilhelm Reich y se hablaba de sexualidad liberada, pero que era mayormente para varones.

Por lo tanto, sostiene que los orígenes del feminismo, del ecologismo y del nuevo pacifismo que cuajarían como movimientos en las dos décadas siguientes no están en Mayo francés y que hay que buscarlos en otros sitios: en las universidades norteamericanas, en las manifestaciones británicas contra la guerra (organizadas por el Comité Russell, entre otros), en los discursos de Luther King y en la Universidad Libre de Berlín.

Trat (2008), de igual modo, considera que hubo una trascendente participación de las mujeres en Mayo francés, pero afirma que desde la perspectiva de género, ningún nombre de mujer ha pasado a la Historia ni como protagonista de la revuelta estudiantil ni del posterior movimiento huelguístico. Tampoco hubo, para esta autora, reivindicaciones encaminadas a mejorar la situación de la mujer, sobre todo en el terreno laboral.

La situación, según Trat, fue por diversas razones: la liberación que supuso para estas jóvenes poder participar, codo con codo, con sus colegas masculinos, tras largos años de segregación; la prioridad concedida al triunfo de la Revolución por encima de cualquier otra demanda; el carácter excesivamente violento de algunas de las acciones de protesta de los jóvenes que alcanzaban un cierto protagonismo; la organización poco democrática y casi espontánea del movimiento en general, que, de haber sido más participativo, hubiera aupado a ciertas mujeres a la cabeza de este.

Prudhomme (2018) testimonia que en el movimiento de Mayo del 68, a pesar de algunos indicios, la visibilidad de las mujeres tampoco se manifestó, fue "igual a cero", y que sus reivindicaciones se expresan durante los meses sucesivos y más ampliamente a partir de las asambleas generales no mixtas en Bellas Artes en 1970.

Recuerda que el movimiento francés para la planificación familiar, representado en el Movimiento de Liberación de la Mujeres (MLF), existía desde 1960 y, algunos meses antes de mayo de 1968, en diciembre de 1967, la ley Neuwirth adoptada en la Asamblea Nacional, autorizó la anticoncepción y especialmente la pastilla anticonceptiva.

Para ella, esta ley fue un primer paso hacia la revolución de las mujeres, porque puso parcialmente fin a la ley de 1920 que prohibía la anticoncepción y el aborto, y que tipificaba el aborto "crimen contra el Estado" susceptible de la pena de muerte, como ocurrió en 1943 cuando fue guillotinada una mujer acusada de haber practicado abortos.

Reconoce que si bien es cierto que desde 1967 el derecho a la concepción cambió la relación de las mujeres con la pareja, la sexualidad, la familia, la maternidad, el trabajo o la ambición personal; tal realidad, constituida por la ley Neuwirth y la planificación familiar, solo representaba indicios, intentos de visibilidad. 
Considera que estos indicios, sin embargo, no fueron registrados por los militantes del 68 y que esa, por consiguiente, es una de las mayores aporías del movimiento de Mayo francés. El sujeto del discurso, subraya, era evidentemente masculino animado de una sexualidad masculina y sin importarles los riesgos de un embarazo no deseado y de un aborto clandestino, peligroso y a veces mortal.

Badenes (2018) manifiesta que el feminismo en Francia se reactivó, en parte, gracias al impulso dado por Mayo del 68, y que muchos de los rasgos del conocido como feminismo de segunda ola bebían de este acontecimiento.

El Mayo francés, resalta la autora, fue el despertar de muchos aspectos positivos que todavía hoy disfrutamos, y que sin ir más lejos, "le debemos la revitalización del movimiento feminista de los setenta, la denominada segunda ola", según la clasificación anglosajona ( $p$. $54)$.

Prudhomme (2018) establece que Mayo del 68 fue decisivo para impulsar a reivindicar los derechos de la mujer, arrastró la radicalización del movimiento para la planificación familiar, impulsó la libertad de las mujeres, se convirtió en el camino fértil en el que germinaron el feminismo y otros movimientos alternativos. Confiesa que es difícil dar una fecha del real origen del Movimiento de Liberación de las Mujeres (MLF), para unas es el 68, para otras el 70-71; pero destaca que resulta claro que Mayo del 68 dio los primeros empujes a través del impulso para la libertad de las mujeres. El movimiento de las mujeres, después, se hace global y trasversal, abraza la defensa de sus propias causas y con la misma fuerza las causas mundiales, motivado por el desbordante espíritu de solidaridad internacional.

\section{CONCLUSIONES}

Mayo francés fue, en primer lugar, una rebelión estudiantil libertaria de rechazo a la sociedad conservadora, a las normas rígidas y a toda forma de autoritarismo, desde lo familiar hasta lo político, que se gesta en las universidades francesas de Nanterre y la Sorbona, a partir de la influencia de una serie de condicionantes (estudiantiles, sociales, económicas, políticas, culturales), movimientos contestatarios, ideas y protestas previas en el ámbito nacional como en el internacional, y cuyo impacto estremece Francia, genera la crisis política que termina con la carrera del líder de la Quinta República y presidente Charles de Gaulle, se extiende a los demás países industrializados y al mundo, convirtiéndose en un movimiento masivo y global, y en todo un símbolo de la protesta juvenil mundial, cuya herencia, por los múltiples enfoques, la amplitud y la complejidad del fenómeno, hasta hoy se trata de explicar.

Segundo, fue un movimiento de estudiantes de izquierda, contraculturales, contestatarios, que indignado por el autoritarismo y el imperialismo reinante en la sociedad francesa, buscó no el control del poder, sino el cambio del statu quo, la reivindicación de libertades en la esfera privada, el establecimiento, en fin, de una sociedad de derechos, todo desde una posición radical e independiente del control político aun del Partido Comunista tradicional al que cuestionaban por claudicar frente al poder de turno y ser inconsecuente ante la real demanda social. Aunque el movimiento no logró de inmediato el cambio de la sociedad autoritaria, sí marcó las huellas para dicho cambio en lo sucesivo por el estremecedor impacto mundial alcanzado.

Tercero, Mayo francés fue un movimiento liderado por los estudiantes universitarios al que por el auge de la protesta se sumaron inmediatamente los obreros, intelectuales y demás fuerzas. Los jóvenes surgen como actor social y político y desplazan del liderazgo a los 
obreros, considerados en la época los actores principales y sujetos revolucionarios por el comunismo, quienes entran en la protesta aun en contra de la resistencia inicial del Partido Comunista y de los líderes de los gremios que el comunismo controlaba.

Cuarto, fue un movimiento con espíritu de cambio real, identificado con un profundo sentimiento de rechazo a la injusticia, como destaca Hildebrandt (2008), "una revolución que no prosperó" pero que "transformó ideas y valores morales", como resalta Dusster (2018), cuyo impacto es percibida hasta hoy como una herencia positiva en la población y como una amenaza en la clase política francesa, o como una "inmortal herencia a liquidar" confesada por Nicolás Sarkosy; y no constituyó un simple movimiento lúdico, una protesta lúdica o una gran fiesta lúdica como, a decir de Fernández Buey (2008), han tratado de banalizar y descalificar los detractores, o de desnaturalizar y estigmatizar la manipulación mediática.

Quinto, el denominado individualismo contemporáneo no fue fruto del discurso o expresión del movimiento, sino de los que vencieron a los estudiantes y obreros, o del "matrimonio de estos con quienes, habiendo perdido, se resignaron para acomodarse a la derrota", como también sostiene Fernández Buey (2008).

Sexto, Mayo del 68 influyó en la reivindicación de los derechos de la mujer, en la relación entre hombres y mujeres, en las relaciones familiares, logros que reconoce públicamente la población a través del sondeo explicado.

Séptimo, la mujer antes de Mayo del 68 vivía, como confiesa Prudhomme (2008), en una sociedad "encorsetada, sofocante, irrespirable, basada en estrictas relaciones de dominación", por lo que sus reivindicaciones no se tomaban en cuenta en ningún aspecto, y que las relaciones de dominación eran sacudidas en las universidades, en las fábricas, en los hospitales, pero no en las que regían las relaciones entre los hombres y las mujeres. La situación se mantuvo aun durante las protestas en las que a las mujeres, como testimonia Fernández Buey (2008), apenas se las dejaba tomar la palabra en los comités. Para Prudhomme (2018), el sujeto del discurso seguía siendo masculino y que pese a algunos indicios de visibilidad de las mujeres, no fueron consideradas por los militantes del 68, hecho que según ella, es una de las mayores aporías del movimiento. La izquierda francesa ortodoxa, como sostiene Badenes (2018), veía el feminismo como una forma de desunión. Y para Trat (2018), entre otros rasgos, el movimiento francés fue una organización poco democrática y casi espontánea. Ello explica por qué las mujeres no visibilizaron un liderazgo individual. A pesar del caso, sin embargo, lo que sí visibilizaron fue un liderazgo colectivo, un protagonismo político colectivo que empieza a ser reconocido en el mundo.

Octavo, si bien es cierto la rebelión de Mayo del 68 visibilizó un liderazgo femenino colectivo e influyó por su intenso ímpetu en la posterior reivindicación de los derechos de la mujer y en el movimiento feminista de segunda ola, no fue el origen directo de este movimiento, ni del ecologismo ni del pacifismo, que junto con estos se fortaleció durante los setenta.

\section{REFERENCIAS BIBLIOGRÁFICAS}

Albiac, G. (1993). Mayo del 68: una educación sentimental. Madrid, España: Temas de Hoy. Badenes, P. (2018). "Transformar la sociedad. Cambiar la vida". Mujeres españolas ante el Mayo francés. Dossiers Feministes, 24, 53-74. doi: http://dx.doi.org/10.6035/Dossiers.2018.24.5 
Dusster, D. (6 de mayo de 2018). 50 años de la revuelta estudiantil: El Mayo del 68 en diez claves. La Vanguardia. Recuperado de: https://www.lavanguardia.com/internacional/20180506/443237104279/mayo-68franciarevolucion.html

Estefanía, J. (2018). Revoluciones: Cincuenta años de rebeldía (1968-2018). España: Galaxia Gutenberg.

Fernández-Buey, F. (2008, 11 de mayo), Tres pistas para intentar entender Mayo del 68. Sin Permiso. Recuperado de https://www.sinpermiso.info/textos/tres-pistas-para-intentarentender-mayo-del-68

Hildebrandt, C. (30 de agosto de 2008). Generación del 68. La Primera, p. 4.

Otero, L. (2008). La larga sombra de Mayo del 68. Dossiers Feministes, 12, 49-68. Recuperado de: file:///C:/Users/Victor/Downloads/140706Texto\%20del\%20art\%C3\%ADculo-191948-1-10-20091019\%20(3).pdf

Prudhomme, F. (2018, 11 de abril). Cincuentenario de 1968: El 22 de marzo de 1968, mayo del 68 y las mujeres. Viento Sur. Recuperado de: https://vientosur.info/el-22-demarzo-de-1968-mayo-del-68-y-las-mujeres/

Rieznik, P., Rabey P., Poy, L., Duarte, D., y Bruno, D. (2010). 1968, un año revolucionario. Buenos Aires, Argentina: Editorial de la Facultad de Filosofía y Letras de la Universidad de Buenos Aires.

Sánchez-Prieto, J. M. (2001). La historia imposible del Mayo francés. Revista de Estudios Políticos, 2(112), 109-133. Recuperado de: file:///C:/Users/Victor/Downloads/DialnetLaHistorialmposibleDelMayoFrances-27654\%20(2).pdf

Struyf, E. (4 de mayo de 2008). 40 años de Mayo del 68. El Comercio, cuerpo B, pp. 1-2.

Trat, J. (2008). Feminismo. En M. Garí, J. Pastor y M. Romero (Eds.), 1968. El mundo pudo cambiar de base (pp. 122-143). España: Los Libros de la Cataratal. 